\title{
Sustainable Food Production Systems for Climate Change Mitigation: Indigenous Rhizobacteria for Potato Bio-fertilization in Tanzania
}

\author{
Becky Nancy Aloo, Ernest Rashid Mbega, and \\ Billy Amendi Makumba
}

\section{Contents}

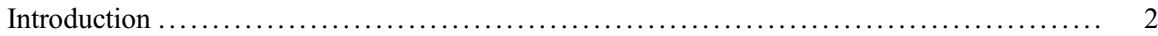

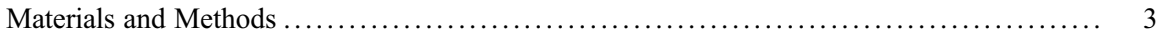

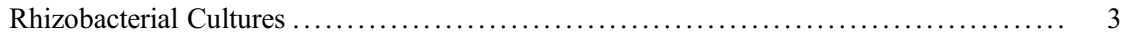

Cultural, Microscopic, and Biochemical Characterization of the Rhizobacterial Cultures ... 3

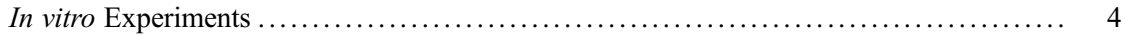

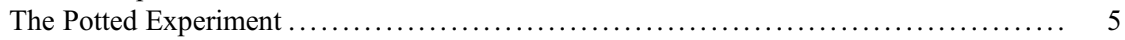

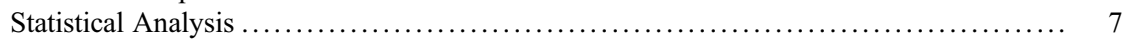

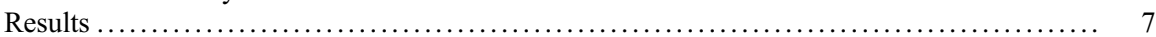

The Cultural, Microscopic, Biochemical, and Carbohydrate Utilization Properties of the

Potato Rhizobacterial Isolates ............................................. 7

In vitro Plant Growth Promoting Abilities of the Potato Rhizobacterial Isolates ......... 11

Effects of the Rhizobacterial Treatments on Potato Growth Parameters and Rhizobacterial

Soils in the Screen House Experiment ..................................... 13

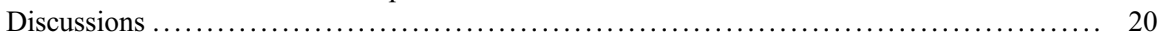

Cultural, Microscopic, Biochemical, and Carbohydrate Utilization Properties of the

Isolates .............................................................. 20

In vitro Plant Growth-Promoting Activities of the Potato Rhizobacterial Isolates ........ 21

Effects of the Rhizobacterial Treatments on Growth and Yield of Potted Potatoes ........ 22

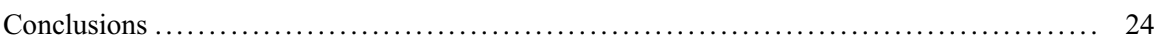

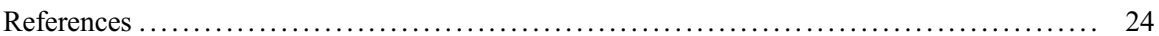

B. N. Aloo $(\bowtie)$

Department of Sustainable Agriculture and Biodiversity Conservation, Nelson Mandela African Institution of Science \& Technology, Arusha, Tanzania

Department of Biological Sciences, University of Eldoret, Eldoret, Kenya

e-mail: aloob@nm-aist.ac.tz

E. R. Mbega

Department of Sustainable Agriculture and Biodiversity Conservation, Nelson Mandela African Institution of Science \& Technology, Arusha, Tanzania

e-mail: ernest.mbega@nm-aist.ac.tz

B. A. Makumba

Department of Biological Sciences, Moi University, Eldoret, Kenya

(C) The Author(s) 2021

W. Leal Filho et al. (eds.), African Handbook of Climate Change Adaptation, https://doi.org/10.1007/978-3-030-42091-8_276-1 


\section{Abstract}

The global rise in human population has led to the intensification of agricultural activities to meet the ever-rising food demand. The potato (Solanum tuberosum L.) is a crop with the potential to tackle food security issues in developing countries due to its short growth cycle and high nutrient value. However, its cultivation is heavily dependent on artificial fertilizers for yield maximization which culminates in global warming and other environmental problems. There is need, therefore, for its alternative fertilization technologies to mitigate climate change. This study evaluated the potential of indigenous rhizobacteria for potato cropping in Tanzania. Ten potato rhizobacterial isolates belonging to Enterobacter, Klebsiella, Citrobacter, Serratia, and Enterobacter genera were obtained from a previous collection from different agro-ecological areas in Tanzania. The isolates were characterized culturally, microscopically, biochemically, and by their carbohydrate utilization patterns. Their in vitro plant growth-promoting (PGP) traits such as nitrogen fixation, solubilization of phosphates, potassium, and zinc, and production of siderophores, indole acetic acid, and gibberellic acids were then evaluated. Lastly, sterilized potato seed tubers were bacterized with the inoculants and grown in pots of sterile soil in a screen-house using untreated plants as a control experiment. The potato rhizobacterial isolates had varying characteristics and showed varying in vitro PGP activities. The screen-house experiment also showed that the rhizobacterial treatments significantly $(p<0.05)$ enhanced different parameters associated with potato growth by up to $91 \%$ and established the potential of most of the isolates as alternative biofertilizers in potato cropping systems in Tanzania.

\section{Keywords}

Potato $\cdot$ Biofertilizer $\cdot$ Plant growth promoting rhizobacteria (PGPR) $\cdot$ Climate change $\cdot$ Sustainable agriculture

\section{Introduction}

Potato (Solanum tuberosum L.) is an important crop for food and economic security in developing countries (FAO 2008). However, its cultivation is heavily dependent on the application of synthetic fertilizers (George and Ed 2011). The general recommendations of synthetic fertilizers for this crop are 120, 123, and 149$199 \mathrm{~kg} \mathrm{ha}^{-1}$ of nitrogen $(\mathrm{N})$, phosphorus $(\mathrm{P})$, and potassium $(\mathrm{K})$, respectively, for an average fresh tuber yield of $30 \mathrm{t} \mathrm{ha}^{-1}$ (Manzira 2011). Nevertheless, these generous fertilizer applications do not always produce the desired results because the crop's rooting system is too shallow for the efficient recovery of fertilizers (Hopkins et al. 2014). 
Attempts to establish suitable alternative fertilization mechanisms for crops to minimize environmental impacts and mitigate climate change are quickly gathering momentum worldwide (Kumar et al. 2018). In this context, plant rhizospheres have been the center of attention worldwide for decades. Plant roots secrete nutrient-rich exudates that attract plant growth-promoting rhizobacteria (PGPR) that contribute to plant growth promotion (PGP) directly or indirectly, for instance, through the production of phytohormones and siderophores, solubilization of phosphates, and biological nitrogen fixation (BNF) (Kumar et al. 2018).

Biofertilizers are PGPR-cultures which are developed for use as inoculants to improve soil fertility and plant productivity (Aloo et al. 2019). The PGPR of different crops like legumes have extensively been studied as biofertilizers, but the potato rhizobacterial communities are not yet fully understood, yet they could extremely be important as alternative biofertilizers for this crop. Understanding their interactions with the potato to unravel their PGP potentials for sustainable potato cropping is equally important. It is now known that indigenous PGPRs of specific crops can make better biofertilizers because they are completely adapted and established in specific environments and can be more competitive than introduced inoculants (Sood et al. 2018). Cognizant of this, the present study was designed to explore the PGP functions of indigenous rhizobacterial strains selected from a previous study that had isolated, and identified rhizobacteria from potato rhizospheres and tubers from different agro-ecological regions in Tanzania. The selected rhizobacteria were studied culturally, microscopically, biochemically and based on their carbohydrate $(\mathrm{CHO})$-utilization patterns. Their in vitro PGP functions and effects on various growth parameters of potato in pot experiments were investigated under screen-house conditions, using un-inoculated potato plants as controls. Understanding these bacteria and their functions can enable the identification of suitable inoculants for the development of sustainable potato cropping systems in Tanzania and provide deeper insights into the overall mitigation of climate change in Africa.

\section{Materials and Methods}

\section{Rhizobacterial Cultures}

Ten rhizobacterial cultures that had previously isolated from potato rhizosphere soils growing in various regions in Tanzania and identified using their 16S rRNA gene sequences (Aloo et al. 2020) were selected for the present study. The strains, sources, and species of these rhizobacterial cultures are displayed in Table 1.

\section{Cultural, Microscopic, and Biochemical Characterization of the Rhizobacterial Cultures}

The morphological characterization of the rhizobacterial colonies was performed based on their sizes, shapes, colors, margins, opacity, elevation, and texture as 
Table 1 Strains, sources, and species of the potato rhizobacterial isolates used in the study

\begin{tabular}{l|l|l|l}
\hline SN & Strain code & Source & Strain identity \\
\hline 1 & LUTS1 & Luteba & Klebsiella grimontii LUTS1 \\
\hline 2 & LUTS2 & Luteba & Enterobacter tabaci LUTS2 \\
\hline 3 & MWAKS1 & Mwakaleli & Klebsiella oxytoca MWAKS1 \\
\hline 4 & MWAKS5 & Mwakaleli & Enterobacter asburiae MWAKS5 \\
\hline 5 & MATS3 & Matadi & Enterobacter tabaci MATS3 \\
\hline 6 & MPUS2 & Mpunguti & Enterobacter tabaci MPUS2 \\
\hline 7 & KIBS5 & Kibuko & Serratia liquefaciens KIBS5 \\
\hline 8 & $M W A N S 4$ & Mwangaza & Citrobacter freundii MWANS4 \\
\hline 9 & BUMS1 & Bumu & Enterobacter ludwigii BUMS1 \\
\hline 10 & NGAS9 & Ngarenairobi & Serratia marcescens NGAS9 \\
\hline
\end{tabular}

described by Somasegaran and Hoben (1994). The determination of Gram staining properties was performed using the $3 \%$ potassium hydroxide $(\mathrm{KOH})$ string test (Pradhan 2016). Rhizobacterial smears were prepared and stained with safranin and observed under oil immersion $(\times 100)$ on a fluorescence microscope (Optika B-350) to determine the cell shapes. Evidence of flagella motility was checked in a motility test medium (MTM).

The qualitative assessment for the production of organic acids was determined using the methyl red (MR) (Sambrook and Russell 2001). The catalase test was used to identify isolates that produced catalases and the citrate test was used to detect the ability of the rhizobacterial isolates to utilize citrate as the sole source of carbon and energy on Simmons citrate agar (Simmons 1926). The ability of the isolates to produce hydrogen sulfide $\left(\mathrm{H}_{2} \mathrm{~S}\right)$ was checked on sulfur indole motility (SIM) agar tubes, and the oxidative-fermentative $(\mathrm{O}-\mathrm{F})$ test medium was used to evaluate the oxidative and fermentative abilities of the isolates. The production of indole by the isolates was also performed on SIM cultures using Kovac's reagent. Lastly, the CHO utilization patterns of the isolates were glucose, sucrose, mannitol, maltose, dextrose, lactose, fructose, dulcitol, sorbitol, trehalose, cellobiose, and ribose as described by Hugh and Leifson (1953).

\section{In vitro Experiments}

The rhizobacterial cultures were screened for various in vitro PGP activities. Pikovskaya's medium containing tricalcium phosphate (TCP) (Wahyudi et al. 2011) and Aleksandrov's medium containing potassium alumino-silicate (Sindhu et al. 1999) were used to evaluate for $\mathrm{P}$ and $\mathrm{K}$ solubilization by the rhizobacterial strains, respectively. Zinc solubilization assays were performed using $\mathrm{ZnO}$ as the insoluble $\mathrm{Zn}$ source (Fasim et al. 2002). For the quantitative estimation of P, K, and $\mathrm{Zn}$ solubilization, the optical densities (OD) of culture supernatants from Pikoskaya's, Alexandrov's, and $\mathrm{ZnO}$ broths were determined spectrophotometrically at $\mathrm{A}_{690}, \mathrm{~A}_{799}$, and $\mathrm{A}_{399}$, respectively, using a multimode reader (Synergy HTX - 
Biotek). The quantities of solubilized $\mathrm{P}, \mathrm{K}$, and $\mathrm{Zn}$ in $\mathrm{mg} \mathrm{L}^{-1}$ were subsequently calculated from standard curves of $\mathrm{KH}_{2} \mathrm{PO}_{4}, \mathrm{KCl}$, and $\mathrm{ZnSO}_{4}$, respectively. The halozones around the bacterial colonies on the plates of respective insoluble compounds were measured and used to compute the solubilization index (SI) for each compound using Eq. 1 (Edi-Premona et al. 1996).

$$
\text { Solubilization index }(\mathrm{SI})=\frac{\text { Colony Diameter }(\mathrm{cm})+\text { Halozone Diameter }(\mathrm{cm})}{\text { Colony Diameter }(\mathrm{cm})}
$$

The production of IAA and GA by the isolates was evaluated as previously described by Vincent (1970) and Holbrook et al. (1961), respectively. The nitrogenase activities of the isolates were checked on solid and liquid N-free media (NFM). The formation of brown or yellow colors in the NFM broth cultures indicated $\mathrm{NH}_{3}$ production, and its OD was measured spectrophotometrically at $435 \mathrm{~nm}$. The concentration of $\mathrm{NH}_{3}$ was then estimated by comparing the absorbance of samples with a standard curve of ammonium sulfate in the range of $0.0-10 \mathrm{mg} \mathrm{L}^{-1}$ (Goswami et al. 2014). The siderophore production abilities of the isolates were assessed using chrome azurol S (CAS) liquid assays and agar plates as described by Schwyn and Neilands (1987). In the liquid CAS assays, the percent siderophore units (\% SU) per isolate were calculated from the absorbance measurements of samples and reference solutions using Eq. 2 (Payne 1993).

$$
\begin{aligned}
\% \text { Siderophore units }(\% \mathrm{SU})= & \frac{\text { Reference absorbance }- \text { Sample absorbance }}{\text { Reference absorbance }} \\
& \times 100 \%
\end{aligned}
$$

For the solid CAS assays, each experiment was performed in triplicates and the diameters of the orange or yellow halozones were used to calculate the siderophores production index (SI) using Eq. 3 (Batista 2012).

$$
\text { Siderophore production index }(\mathrm{SI})=\frac{\text { Orange halozone }(\mathrm{cm})}{\text { Colony diameter }(\mathrm{cm})}
$$

\section{The Potted Experiment}

The rhizobacterial cultures were grown in $50 \mathrm{~mL}$ universal bottles filled with $25 \mathrm{~mL}$ Tryptic soy broth in a rotary shaker $(200 \mathrm{rpm})$ for $16 \mathrm{~h}$ at $28^{\circ} \mathrm{C}$. The absorbance of the bacterial suspensions was evaluated spectrophotometrically at $600 \mathrm{~nm}$ using a multimode reader (Synergy HTX - Biotek), and each culture was diluted in sterile distilled water to a final concentration of $1 \times 10^{6} \mathrm{CFUs} \mathrm{mL}^{-1}$. The cells were harvested by centrifugation at $4000 \mathrm{rpm}$ for $20 \mathrm{~min}$ at $4{ }^{\circ} \mathrm{C}$ and resuspended in $100 \mathrm{~mL}$ of $7 \%$ Carboxy Methyl Cellulose (CMC) solution to help bind the cells to the tubers. Potato seed tubers sourced from a nearby local market were surface- 
sterilized (using 3\% sodium hypochlorite for $3 \mathrm{~min}$ and rinsing four times in sterile distilled water). The tubers suspended in the prepared bacterial suspensions for $30 \mathrm{~min}$ and sown in plastic pots (20 cm wide) containing $250 \mathrm{~g}$ of $24-\mathrm{h}$ ovensterilized soil with $\mathrm{pH}$ : 7.33 , electrical conductivity (EC): $207.33 \mu \mathrm{S} \mathrm{cm}^{-1}$, soluble salts: $0.07 \%$, organic carbon $(\mathrm{OC}): 0.89 \%$, organic matter $(\mathrm{OM}): 1.53 \%, \mathrm{~N}: 0.08 \%$, zinc $(\mathrm{Zn}): 35.62 \mathrm{mg} \mathrm{kg} \mathrm{kg}^{-1}, \quad \mathrm{P}: 231.64 \mathrm{mg} \mathrm{kg}^{-1}, \mathrm{~K}: 7.59 \mathrm{mg} \mathrm{kg} \mathrm{kg}^{-1}$, iron (Fe): $1.31 \mathrm{mg} \mathrm{kg}^{-1}$, sand: $68.67 \%$, clay + silt: $29.44 \%$ and gravel: $1.88 \%$. The experiment was set up in a completely randomized block design with three replicate potato pots per treatment, giving a total of 93 pots for 90 bacterized tubers (10 isolates in three triplicates) and three nonbacterized tubers. The screen house conditions were naturally maintained at $20-22{ }^{\circ} \mathrm{C}$ with a day length of $12 \mathrm{~h}$ and watered every $48 \mathrm{~h}$ using sterile distilled water $\left(150 \mathrm{~mL} \mathrm{pot}^{-1}\right)$.

The number of days to emergence (DTE) and flowering (DTF) per treatment was recorded and 90 days after planting (DAP), the crops were harvested and data obtained on the number of tubers, length and weight of shoots, and the average weight and size of tubers per plant. To obtain the average size of tubers per plant, the diameter of each tuber from each potato plant was measured using a measuring tape, and the diameter of tubers per plant obtained by dividing the total diameter of tubers per plant by the number of tubers from that plant. The average radius of tubers per plant was obtained by diving the average diameter by two and used to determine the potato tuber size per plant (Eq. 4).

$$
\text { Average tuber size }=\frac{4}{3} \pi \times(\text { Average radius }) 3
$$

The potato rhizospheric soils were evaluated for various physicochemical properties. The $\mathrm{pH}$ and EC of the soils were analyzed by the saturated paste method as proposed by Jackson (1973) and Chi and Wang (2010), respectively. The (\%) OC in the soils was determined by the potassium dichromate $\left(\mathrm{K}_{2} \mathrm{Cr}_{2} \mathrm{O}_{7}\right)$ wet digestion method and the (\%) OM of the samples was derived from the (\%) OC using Eq. 5 (Walkley and Black 1934).

$$
(\%) \text { Organic Matter }=(\%) \text { Organic Carbon } \times 1.724
$$

The $\mathrm{N}$ content in the rhizospheric soils was determined following the microKjeldahl method (Bremmer and Mulvaney 2015). The Mehlich III method was used to extract the soil P and Zn (Tran and Simard 1993), while the extraction of K was performed using the ammonium acetate method (Jackson 1973). The 1, 10phenanthroline complex method described by Chaurasia and Gupta (2014) was used for the extraction of $\mathrm{Fe}$ in the samples. The quantitative estimation of $\mathrm{P}, \mathrm{K}$, $\mathrm{Zn}$, and $\mathrm{Fe}$ in the soil extracts was performed by determining the OD spectrophotometrically at $\mathrm{A}_{690}, \mathrm{~A}_{799}, \mathrm{~A}_{399}$, and $\mathrm{A}_{510}$, respectively, using the multimode reader (Synergy HTX - Biotek) and subsequently calculating their concentrations from standard curves of $\mathrm{KH}_{2} \mathrm{PO}_{4}, \mathrm{KCl}, \mathrm{ZnSO}_{4}$, and ferrous ammonium sulfate, respectively. 
The potato tuber nutrient contents were evaluated per plant from single welldeveloped tubers. The tubers were surface-sterilized using $2 \%$ sodium hypochlorite and rinsed four times with sterile distilled water. Next, they were chopped into small pieces using a clean knife and dried in the oven $\left(80{ }^{\circ} \mathrm{C}\right)$ for 5 days. Particle size reduction was performed by mechanically grinding, crushing, and milling them into fine amorphous powders. The $\mathrm{P}, \mathrm{Fe}$, and $\mathrm{K}$ in them were extracted using $50 \mathrm{~mL}$ of $2 \%$ acetic acid on $0.2 \mathrm{~g}$ of samples, followed by filtering (Miller 1995). The Mehlich III method was used to extract $\mathrm{Zn}$ in the powdered potato tuber samples (Tedesco et al. 1995). All sample extracts were subjected to quantification of $\mathrm{P}, \mathrm{K}, \mathrm{Zn}$, and Fe by absorbance measurements using the multimode reader (Synergy HTX - Biotek), and the respective concentrations were obtained using the standard graphs as previously described for soil analysis. The analysis of total $\% \mathrm{~N}$ in potato samples was performed using the micro-Kjeldahl process (Bremmer and Mulvaney 2015), and their crude protein contents were estimated using Eq. 6 based on the assumption that $\mathrm{N}$ constitutes $16 \%$ of protein (AOAC 1995).

$$
\text { Crude protein content }(\%)=\text { micro }- \text { Kjeldahl } \mathrm{N} \text { content }(\%) \times 6.25
$$

\section{Statistical Analysis}

All statistical analyses were performed using the XLSTAT (Version 2.3, Adinsoft) at a $95 \%$ level of confidence. The Shapiro-Wilk test was used to test for normality of data and multiple comparisons of variances were performed using Multivariate Analysis of Variance (MANOVA). Variables with significantly different means were subjected to post hoc analysis using Tukey's Honest Significant Difference (HSD) test. Spearman's correlation was used to evaluate relationships between potato nutrient contents, rhizosphere soil properties, and potato biometrics in the screen house experiment. The percent increase/decrease in levels of different response/dependent variables was calculated from the field experiments using Eq. 7 to assess the differences between treatment and control experiments.

$$
\frac{\text { Treatment }- \text { Control }}{\text { Treatment }} \times 100 \%
$$

\section{Results}

\section{The Cultural, Microscopic, Biochemical, and Carbohydrate Utilization Properties of the Potato Rhizobacterial Isolates}

The cultural, microscopic, biochemical, and the $\mathrm{CHO}$ utilization properties of the potato rhizobacterial isolates are displayed in Table 2. All colonies were round in form except for E. tabaci MPUS2 and S. liquefaciens KIBS5 which were spreading in form and $C$. freundii MWANS4 which had a rhizoid appearance. They portrayed 


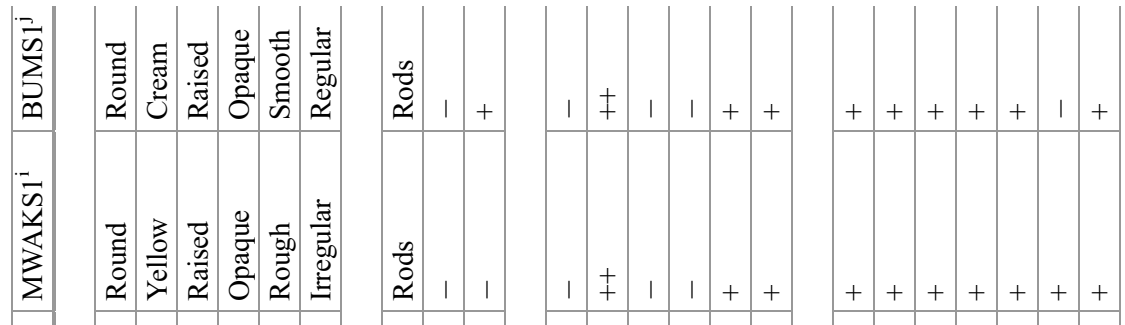

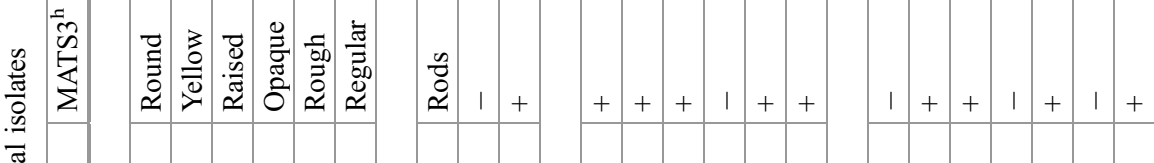

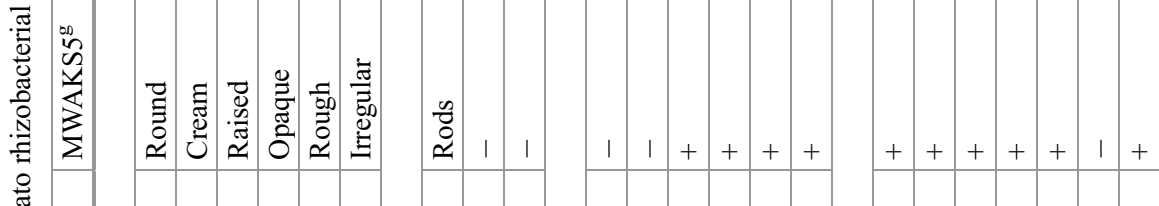

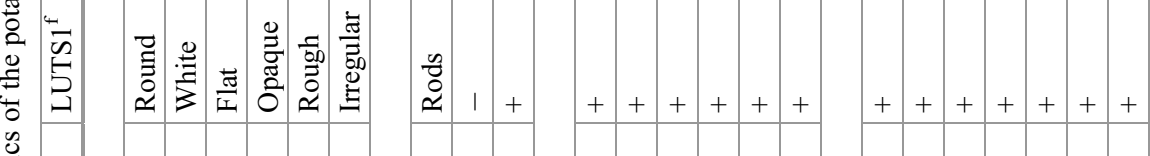

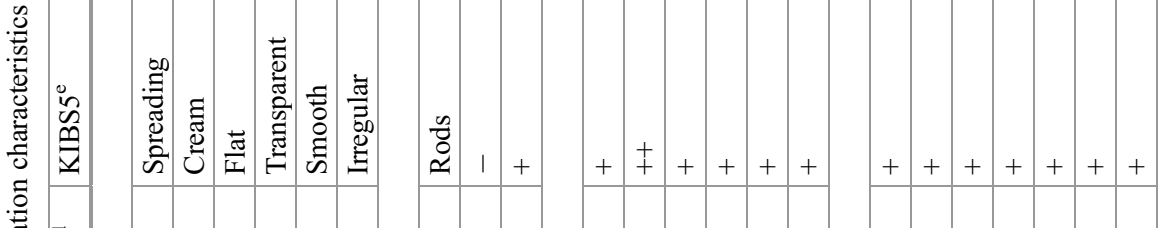

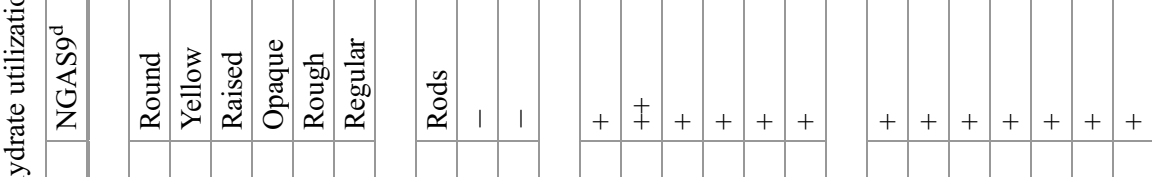

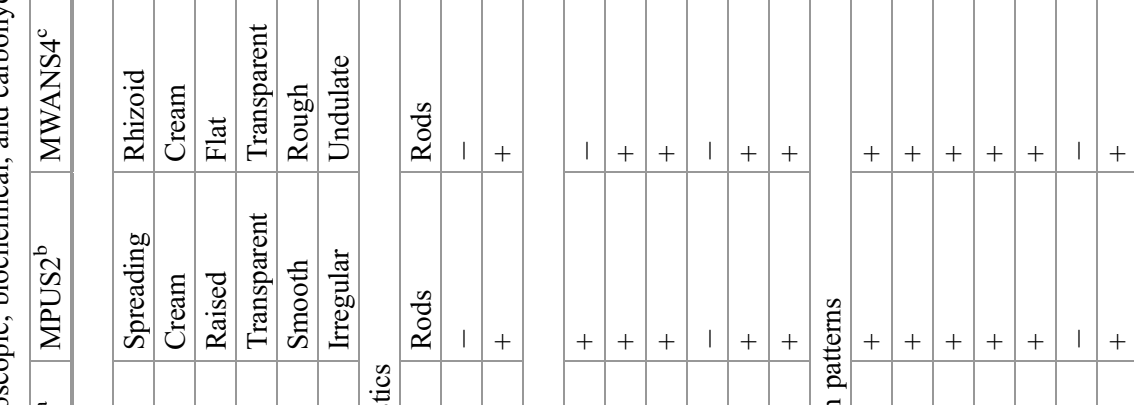

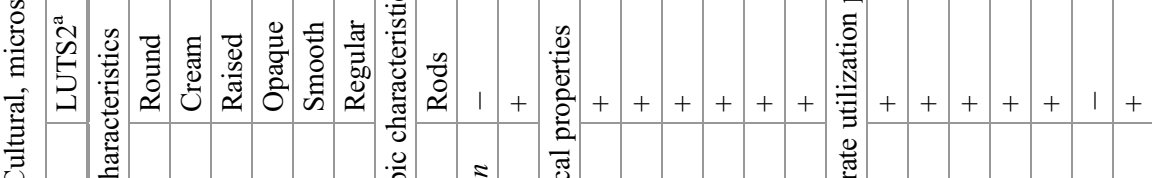

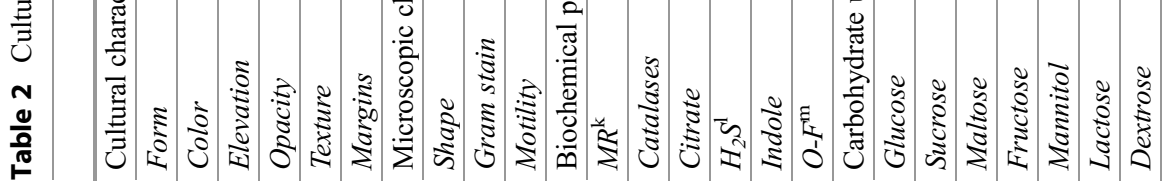




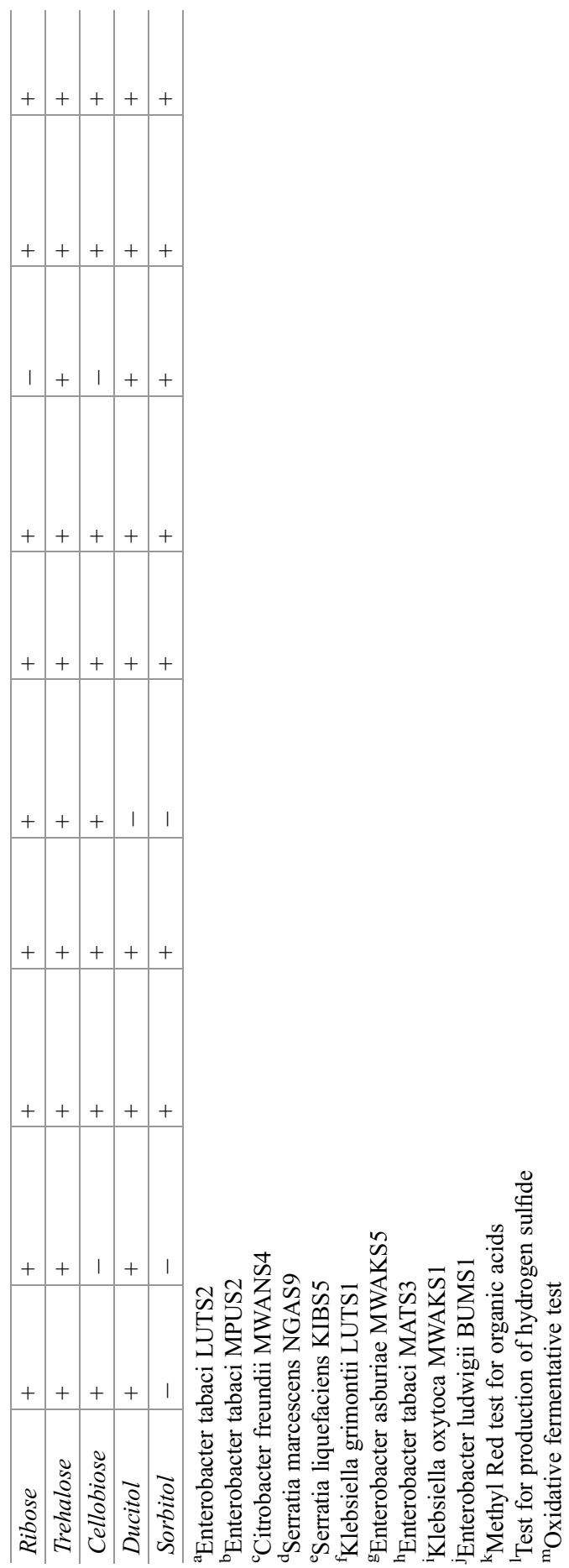




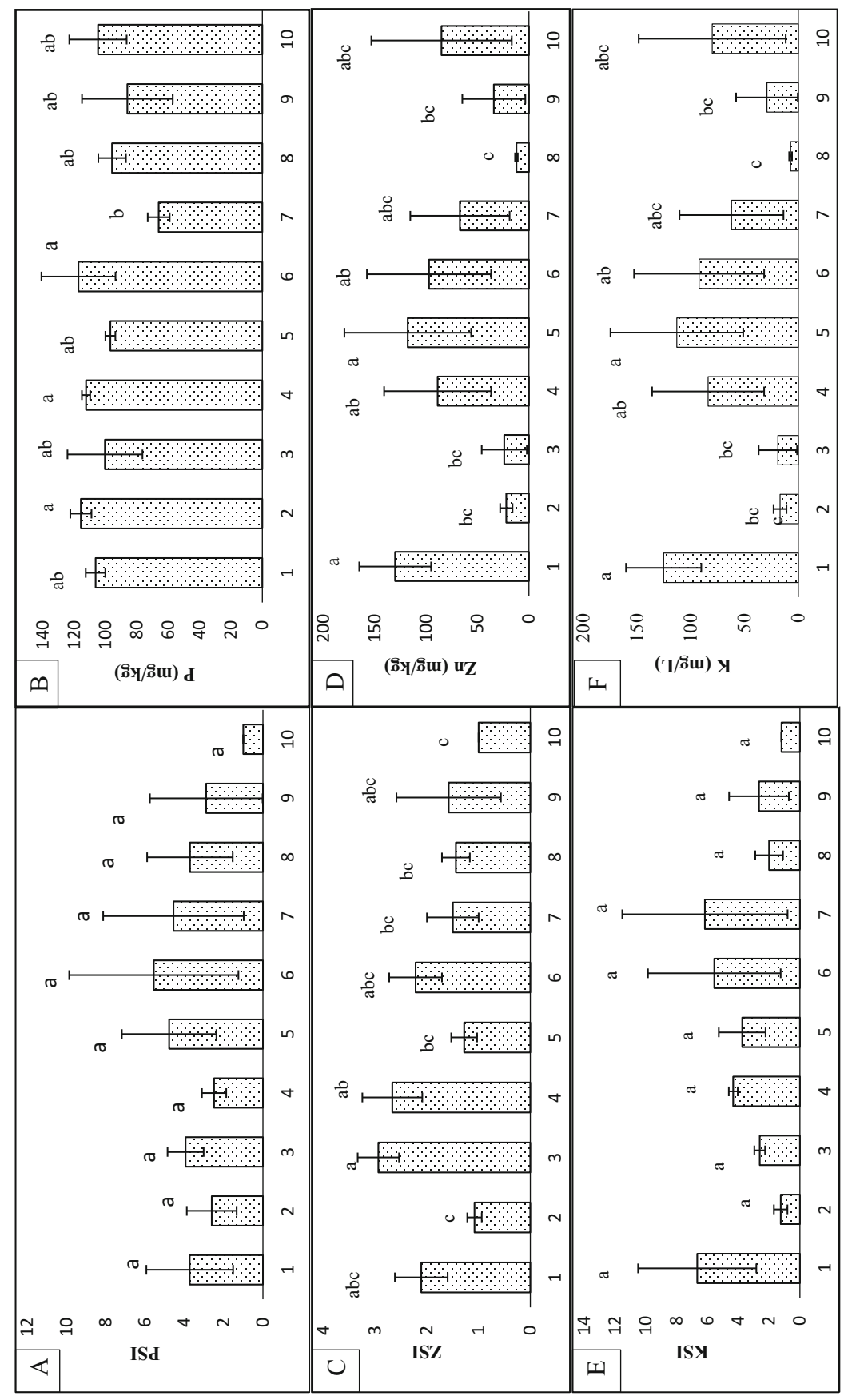

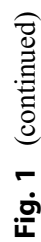


different colors, textures, and margins and most were opaque. All were rod-shaped and Gram-negative. Similarly, all strains were motile except for $S$. marcescens NGAS9, E. asburiae MWAKS5, and $K$. oxytoca MWAKS1 and all were MRpositive except for $C$. freundii MWANS4, E. asburiae MWAKS5, K. oxytoca MWAKS1, and E. ludwigii BUMS1.

Except for E. asburiae MWAKS5, the rest of the studied isolates were catalasepositive, with some isolates like E. ludwigii BUMS1, K. oxytoca MWAKS1, S. liquefaciens KIBS5, and $S$. marcescens NGAS9 exhibiting strong catalase activities than the rest of the isolates. Half of the isolates exhibited $\mathrm{H}_{2} \mathrm{~S}$ production abilities but indole production and O-F tests were positive for all of them. Klebsiella oxytoca MWAKS1, K. grimontii LUTS1, and $S$. marcescens NGAS9 metabolized all the tested sugars. Enterobacter ludwigii BUMS1, E. tabaci MATS3, E. asburiae MWAKS5, C. freundii MWANS4, E. tabaci MPUS2, and E. tabaci LUTS2 could not metabolize lactose. Additionally, E. tabaci MPUS2 and E. tabaci MATS3 could not metabolize cellobiose, E. tabaci LUTS2, E. tabaci MPUS2, and S. liquefaciens KIBS5 could not metabolize sorbitol and $S$. liquefaciens KIBS5 could not metabolize dulcitol.

\section{In vitro Plant Growth Promoting Abilities of the Potato Rhizobacterial Isolates}

The results of in vitro solubilization of $\mathrm{P}, \mathrm{Zn}$, and $\mathrm{K}$ by the 10 potato rhizobacterial isolates are portrayed in Fig. 1a-f. Significant differences among the isolates were observed for ZSI in the qualitative assays and quantities of solubilized $\mathrm{P}(p=0.026), \mathrm{Zn}(p=0.031)$, and $\mathrm{K}(p=0.031)$ in the quantitative assays. However, no significant differences were noted for PSI $(p=0.885)$ and KSI $(p=0.524)$ in the qualitative assays. The averages of PSI, ZSI, and KSI were $3.628 \pm 0.420,1.783 \pm 0.764$, and $3.619 \pm 3.563$, respectively, while those for quantities of solubilized $\mathrm{P}, \mathrm{Zn}$, and $\mathrm{K}$ were $100.33 \pm 19.90 \mathrm{mg} \mathrm{L}^{-1}$, $67.897 \pm 55.46 \mathrm{mg} \mathrm{L}^{-1}$, and $62.897 \pm 55.46 \mathrm{mg} \mathrm{L}^{-1}$, respectively. The best $\mathrm{P}$ solubilizers were E. tabaci LUTS 2, E. tabaci MPUS2, and S. liquefaciens KIBS5 which recorded average quantities of $115.88,112.59$, and $117.43 \mathrm{mg} \mathrm{L}^{-1}$ of solubilized P, respectively. Similarly, S. marcescens NGAS9, with average ZSI of 2.94 and E. ludwigii BUMS1, with an average of $130.26 \mathrm{mg} \mathrm{L}^{-1}$ of solubilized $\mathrm{Zn}$,

Fig. 1 In vitro nutrient solubilization abilities of the potato rhizobacterial isolates. On the $\mathrm{X}$ axes, 1 = Enterobacter ludwigii BUMS1, 2 = Enterobacter tabaci LUTS2, 3 = Serratia marcescens NGAS9, 4 = Enterobacter tabaci MPUS2, $5=$ Citrobacter freundii MWANS, $6=$ Serratia liquefaciens KIBS5, 7 = Klebsiella grimontii LUS1, $8=$ Enterobacter asburiae MWAKS5, $9=$ Klebsiella oxytoca MWAKS1 and $10=$ Enterobacter tabaci MATS3. (a): Phosphorus solubilization index (b): Quantity of solubilized Phosphorus (c): Zinc solubilization index (d): Quantity of solubilized Zinc (e): Potassium solubilization index (f): Quantity of solubilized potassium. Values are means of three replicates and bars with similar letters are not significantly different (ANOVA + Tukey's HSD; $P<0.05$ ) 


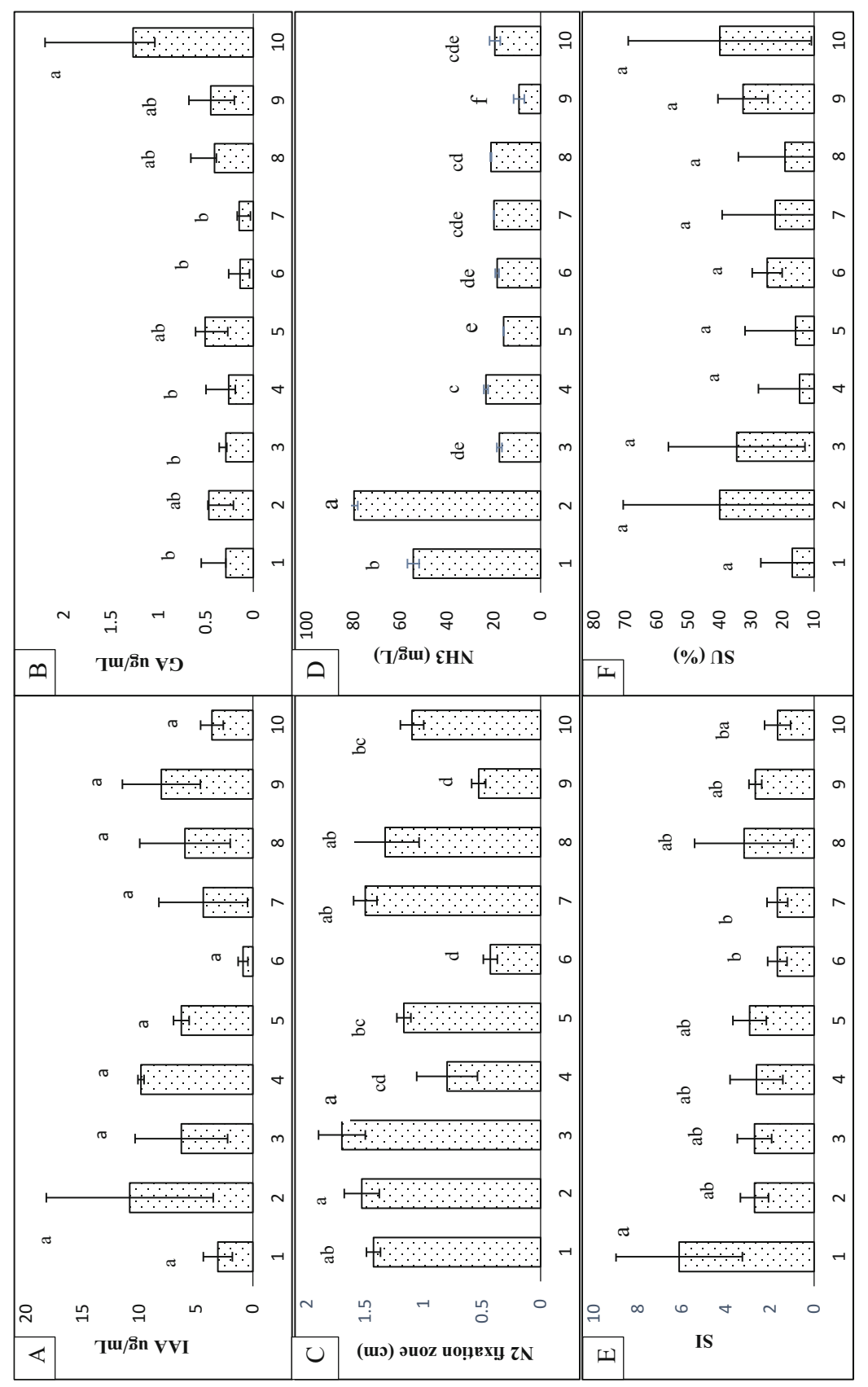

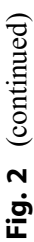


exhibited the best $\mathrm{Zn}$ solubilization abilities in the qualitative and quantitative assays, respectively. Only two isolates, C. freundii MWANS4 and E. ludwigii BUMS1 exhibited good $\mathrm{K}$ solubilization abilities in the quantitative assays by yielding an average of 112.98 and $125.26 \mathrm{mg} \mathrm{L}^{-1}$ of solubilized $\mathrm{K}$, respectively.

The quantity of IAA produced by the potato isolates in vitro was not significantly different ( $p=0.080$ ) (Fig. 2a). Nevertheless, E. tabaci LUTS2 yielded the highest quantity of IAA $\left(10.86 \mu \mathrm{g} \mathrm{mL}^{-1}\right)$ and the average quantity of IAA produced by all the isolates was $5.57 \pm 4.51 \mu \mathrm{g} \mathrm{mL}^{-1}$. Interestingly, the isolates exhibited significantly different ( $p=0.027$ ) abilities to produce GA (Fig. 2b). The average quantity of GA produced by the isolates was however only $0.423 \pm 0.420 \mu \mathrm{g} \mathrm{mL}^{-1}$ and the best GA producer was E. tabaci MATS3 with an average of $1.27 \mu \mathrm{g} \mathrm{mL}^{-1}$. The isolates exhibited significantly different $(p<0.0001) \mathrm{N}_{2}$-fixation abilities in vitro (Fig. 2c, d). The average $\mathrm{N}_{2}$ fixation zones and quantities of ammonia $\left(\mathrm{NH}_{3}\right)$ recorded for them were $1.153 \pm 0.440 \mathrm{~cm}$ and $27.97 \pm 21.09 \mathrm{mg} \mathrm{L}^{-1}$, respectively. Serratia marcescens NGAS9 which recorded an average $\mathrm{N}_{2}$ fixation zone of $1.70 \mathrm{~cm}$ and $E$. ludwigii BUMS1 with an average of $79.84 \mathrm{mg} \mathrm{L}^{-1}$ produced $\mathrm{NH}_{3}$ yielded the best results from the two tests used to assess for in vitro $\mathrm{N}_{2}$ fixation. The isolates exhibited significant differences $(p=0.021)$ with regards to the SI averages (Fig. $2 \mathrm{e})$, but no significant differences ( $p=0584$ ) were observed with regards to the SU averages (Fig. 2f). The average SI and SU recorded for the isolates were $2.79 \pm 1.66$ and $26.14 \pm 18.25 \%$, respectively. The highest average SI of 6.13 was yielded by $E$. ludwigii BUMS1 and the rest of the isolates yielded significantly lower SI averages ranging from 1.67 to 2.71 .

\section{Effects of the Rhizobacterial Treatments on Potato Growth Parameters and Rhizobacterial Soils in the Screen House Experiment}

The effects of rhizobacterial treatments on various growth parameters related to potato growth in the screen house experiment are shown in Table 3. Although the DTE averages were not significantly different for the different treatments in this experiment $(p=0.960)$, treatment with some rhizobacteria such as $K$. oxytoca MWAKS1, E. tabaci LUTS2, and E. asburiae MWAKS5 still resulted in DTE reduction by $7.53 \%, 3.41 \%$, and $7.53 \%$, respectively. Treatment of the potato seed tubers with the various rhizobacterial isolates significantly $(p=0.027)$ improved the

Fig. 2 Effects of rhizobacterial treatments on growth parameters of potted potato plants. On the X axes, 1 = Enterobacter ludwigii BUMS1, 2 = Enterobacter tabaci LUTS2, 3 = Serratia marcescens NGAS9, 4 = Enterobacter tabaci MPUS2, $5=$ Citrobacter freundii MWANS, $6=$ Serratia liquefaciens KIBS5, $7=$ Klebsiella grimontii LUS1, $8=$ Enterobacter asburiae MWAKS5, $9=$ Klebsiella oxytoca MWAKS1 and $10=$ Enterobacter tabaci MATS3. (a): Quantity of Gibberellic acids (b): Quantity of indole-3-acetic acid (c): Nitrogen fixation zone (d): Quantity of ammonia (e): Siderophore production index (f): Siderophore production units. Values are means of three replicates and beans with similar letters within the same chart are not significantly different (ANOVA + Tukey's HSD; $P<0.05$ ) 


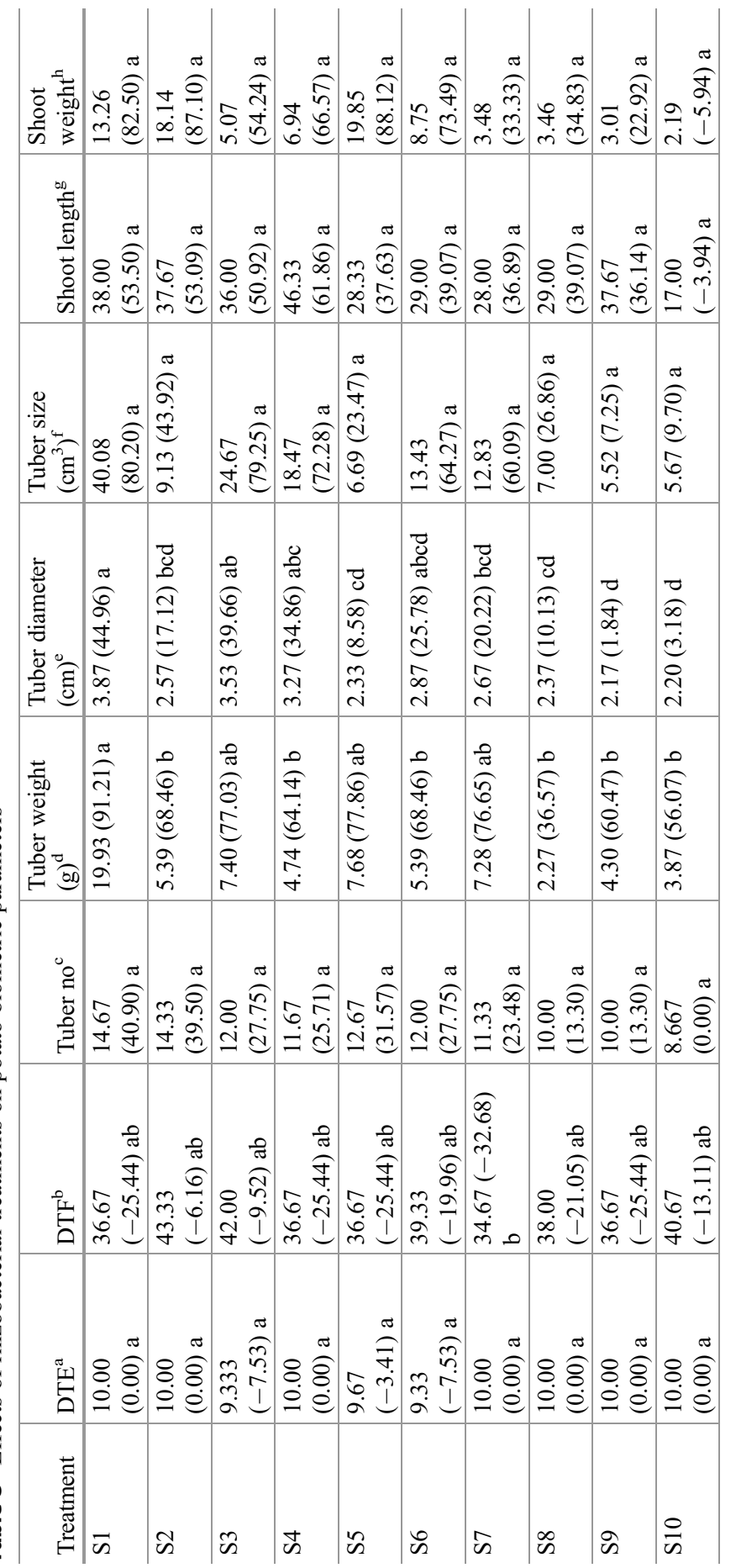




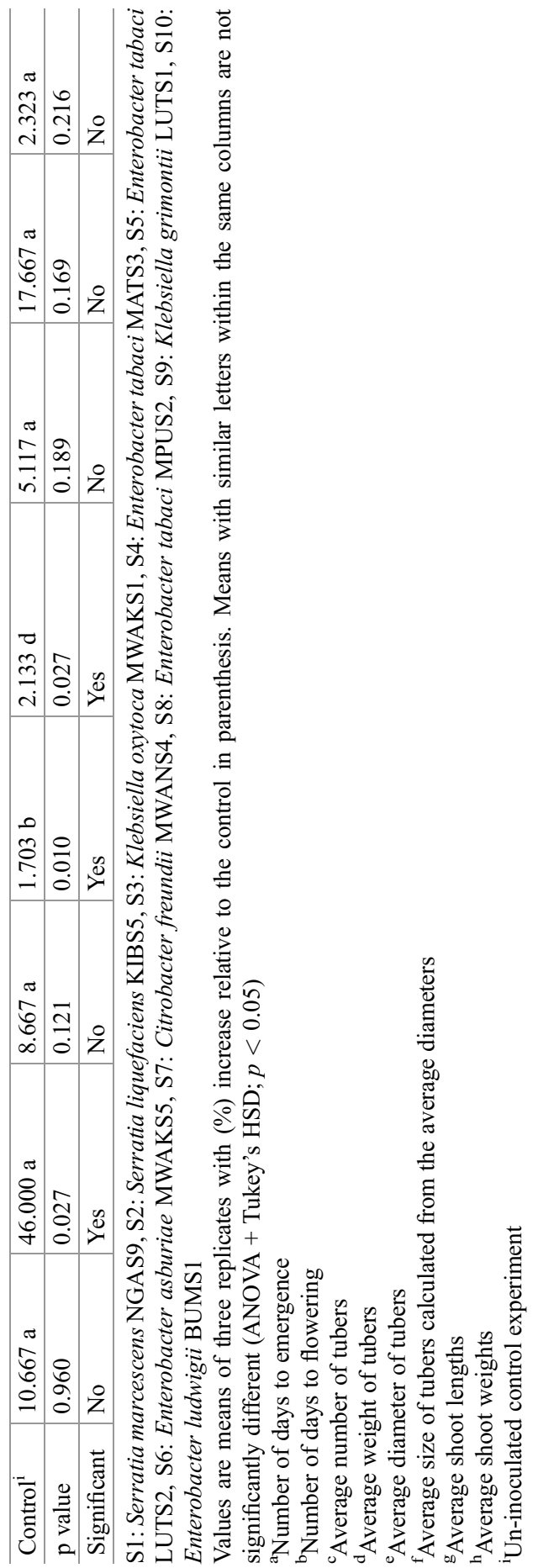


DTF of treated plants in comparison to the untreated controls which recorded the highest DTF of 46. The rhizobacterial treatments reduced the average DTF of potato plants by approximately 6-33\%. The DTF reduction by $C$. freundii of $32.68 \%$ was significantly higher than all other rhizobacterial treatments.

Although the number of tubers was not significantly different $(P=0.121)$ across the different rhizobacterial treatments and the un-inoculated control, the rhizobacterial treatments still resulted in crops with increased tuber yields above the control which recorded an average tuber number of 8.67. The greatest average number of tubers of 14.67 was observed from the treatment with $S$. marcescens $N G A S 9$ corresponding to a $91.21 \%$ increase relative to the control plants. Significant differences were observed for tuber weight $(p=0.010)$ and diameter $(p=0.027)$ among the different rhizobacterial treatments and the uninoculated control plants.

The highest average tuber weight of $19.93 \mathrm{~g}$ corresponding to a $91.21 \%$ increase above the control was recorded for potato plants from the treatment with $S$. marcescens NGAS9. This particular treatment also yielded the largest tuber diameter of $3.87 \mathrm{~cm}$ corresponding to a $44.96 \%$ increase over the control which recorded an average tuber diameter of $2.13 \mathrm{~cm}$.

No significant differences $(p=0.189)$ were observed for tuber sizes for the different treatments and the control experiment. However, treatment with $S$. marcescens NGAS9 produced an average tuber size of $40.08 \mathrm{~cm}^{3}$ corresponding to an increase of $87.23 \%$ above control treatments. The average shoot lengths of potato plants observed for different rhizobacterial treatments in this study were not significantly different $(p=0.169)$. However, all rhizobacterial treatments except for E. ludwigii BUMS1 resulted in increased shoot lengths of the potato plants by between $36 \%$ and $54 \%$ relative to the un-inoculated controls. The treatment with E. tabaci MATS3 gave the maximum shoot weight of 46.33 and the highest increment of $61.86 \%$ relative to the un-inoculated control. Interestingly, treatment with E. ludwigii BUMS1, though not significant, resulted in shoots with lower weights and lengths in comparison to the un-inoculated control. Similarly, the average shoot weights of potato plants observed for different rhizobacterial treatments in this study were not significantly different $(p=0.126)$. However, the treatments still resulted in increased shoot weights of potato plants by up to $82 \%$ relative to the control experiments where the average shoot weight was $2.32 \mathrm{~g}$.

The properties of potato rhizospheric soils from the screen house experiment are provided in Table 4. Significant differences $(p<0.05)$ were among the rhizobacterial treatments and the un-inoculated control for all the studied soil properties except for $\mathrm{Fe}(p=0.077), \mathrm{P}(p=0.109)$, and $\mathrm{pH}(p=0.493)$. The treatment with E. tabaci MPUS2 resulted in the highest OM content of $3.56 \%$ corresponding to a $60 \%$ increment over the un-inoculated control. Klebsiella grimontii LUTS1 also yielded the best results in terms of EC, salts, and K contents with averages of $1467.33 \mathrm{uS} \mathrm{cm}{ }^{-1}, 0.51 \%$, and $31.79 \mathrm{mg} \mathrm{kg}^{-1}$, respectively, corresponding to increments of $48.8 \%, 49.7 \%$, and $75.3 \%$, respectively, above the un-inoculated control. Treatment of potato plants with E. asburiae MWAKS5 also yielded significantly higher averages of OM (2.22\%), OM (3.83\%), and $\mathrm{Zn}$ 


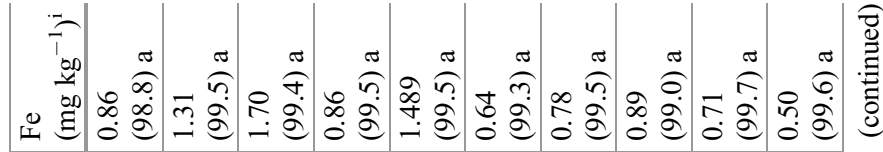

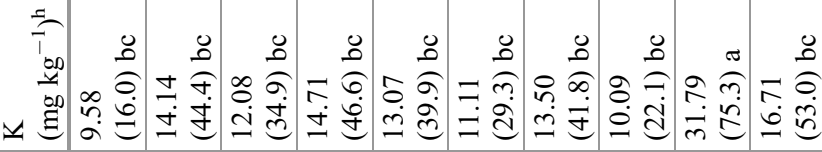

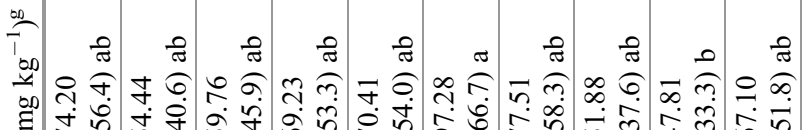

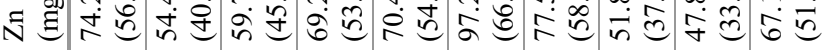

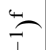

$$
\begin{aligned}
& \text { 电 }
\end{aligned}
$$

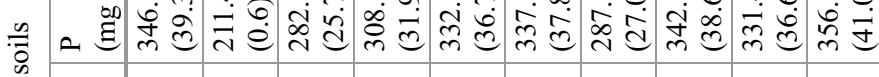

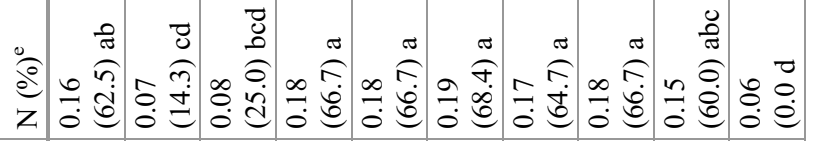




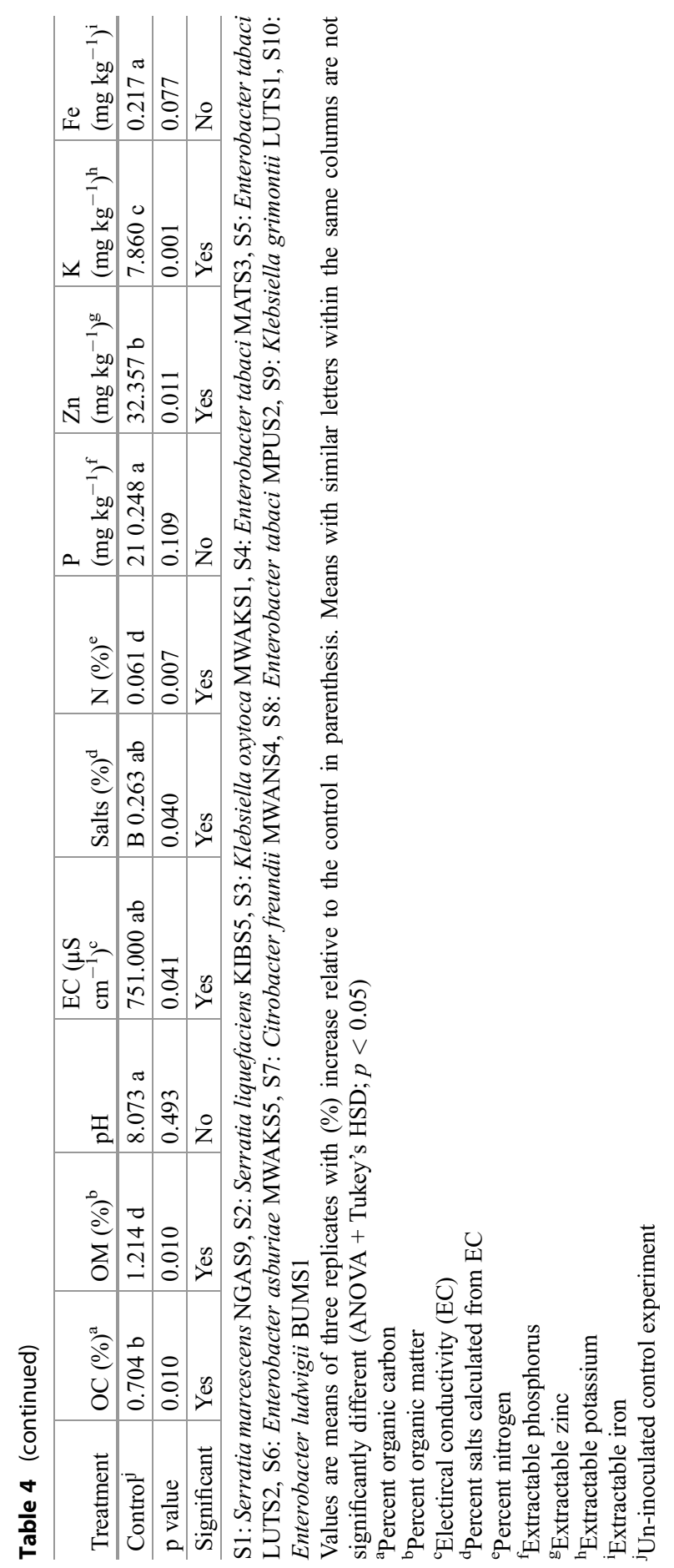


(92.28 $\mathrm{mg} \mathrm{kg}^{-1}$ ) corresponding to increments of $68.3 \%, 68.4 \%$, and $66.7 \%$, respectively, over the un-inoculated control.

Except for $\mathrm{pH}, \mathrm{EC}$, and salt contents, where some treatments resulted in reduced contents and others, increased contents in rhizospheric soils of the treated potato plants, the quantities of the rest of the soil properties increased as a result of the rhizobacterial treatments. Although no significant differences $(p=0.077)$ were noted among the potato rhizobacterial treatments and the un-inoculated control with regards to $\mathrm{Fe}$ contents of the rhizospheric soils, all rhizobacterial treatments resulted in increased $\mathrm{Fe}$ contents of between $99.0 \%$ and $99.8 \%$. The effects of

Table 5 Effects of rhizobacterial treatments on physicochemical properties of potato nutrient contents

\begin{tabular}{|c|c|c|c|c|c|c|}
\hline Treatment & \begin{tabular}{|l|}
$\begin{array}{l}\text { Nitrogen } \\
(\%)\end{array}$ \\
\end{tabular} & \begin{tabular}{|l|}
$\begin{array}{l}\text { Protein } \\
(\%)\end{array}$ \\
\end{tabular} & \begin{tabular}{|l} 
Phosphorus \\
$\left(\mathrm{mg} \mathrm{kg}^{-1}\right)$
\end{tabular} & $\begin{array}{l}\text { Potassium } \\
\left(\mathrm{mg} \mathrm{kg}^{-1}\right)\end{array}$ & $\begin{array}{l}\text { Iron } \\
\left(\mathrm{mg} \mathrm{kg}^{-1}\right)\end{array}$ & \begin{tabular}{|l|}
$\begin{array}{l}\text { Zinc } \\
\left(\mathrm{mg} \mathrm{kg}^{-1}\right)\end{array}$ \\
\end{tabular} \\
\hline S1 & $\begin{array}{l}1.05 \\
(87.6) \mathrm{a}\end{array}$ & \begin{tabular}{|l}
6.55 \\
$(87.1) \mathrm{a}$
\end{tabular} & \begin{tabular}{|l|}
2363.13 \\
$(93.1) \mathrm{a}$
\end{tabular} & $\begin{array}{l}1051.29 \\
(53.7) b c\end{array}$ & $\begin{array}{l}0.59 \\
(62.7) \mathrm{ab}\end{array}$ & \begin{tabular}{|l}
1946.68 \\
$(91.9) \mathrm{cd}$
\end{tabular} \\
\hline S2 & \begin{tabular}{|l}
0.91 \\
$(85.7) \mathrm{a}$
\end{tabular} & \begin{tabular}{|l}
5.69 \\
$(85.4) \mathrm{a}$ \\
\end{tabular} & \begin{tabular}{|l|}
2052.73 \\
$(92.1) \mathrm{a}$ \\
\end{tabular} & $\begin{array}{l}1341.95 \\
(63.8) \mathrm{b}\end{array}$ & $\begin{array}{l}1.07 \\
(79.4) \mathrm{ab}\end{array}$ & \begin{tabular}{|l|}
4101.05 \\
$(96.2) \mathrm{abc}$
\end{tabular} \\
\hline S3 & $\begin{array}{l}0.90 \\
(85.4) \mathrm{ab}\end{array}$ & \begin{tabular}{|l|}
5.62 \\
$(85.2) a b$
\end{tabular} & \begin{tabular}{|l|}
2028.50 \\
$(92.0) \mathrm{ab}$
\end{tabular} & $\begin{array}{l}1489.33 \\
(67.4) \mathrm{b}\end{array}$ & $\begin{array}{l}0.95 \\
(76.8) \mathrm{ab}\end{array}$ & \begin{tabular}{|l|}
1553.80 \\
$(90.0) \mathrm{cd}$
\end{tabular} \\
\hline S4 & $\begin{array}{l}1.00 \\
(86.9) \mathrm{a}\end{array}$ & \begin{tabular}{|l}
6.25 \\
$(86.7) \mathrm{a}$
\end{tabular} & $\begin{array}{l}2256.39 \\
(92.8) \mathrm{a}\end{array}$ & $\begin{array}{l}2741.86 \\
(82.3) \mathrm{a}\end{array}$ & $\begin{array}{l}1.50 \\
(85.3) \mathrm{ab}\end{array}$ & $\begin{array}{l}6429.97 \\
(97.6) \mathrm{a}\end{array}$ \\
\hline S5 & $\begin{array}{l}0.45 \\
(71.11) b c\end{array}$ & $\begin{array}{l}2.81 \\
(70.5) b c\end{array}$ & $\begin{array}{l}1012.16 \\
(83.9) \mathrm{bc}\end{array}$ & $\begin{array}{l}1430.58 \\
(66.0) \mathrm{b}\end{array}$ & $\begin{array}{l}6.63 \\
(96.7) \mathrm{a}\end{array}$ & \begin{tabular}{|l|}
2580.98 \\
$(94.0)$ bcd
\end{tabular} \\
\hline S6 & $\begin{array}{l}0.99 \\
(86.9) \text { a }\end{array}$ & \begin{tabular}{|l}
6.21 \\
$(86.6)$ a
\end{tabular} & $\begin{array}{l}2240.02 \\
(92.7) \mathrm{a}\end{array}$ & $\begin{array}{l}1266.93 \\
(61.6) b c\end{array}$ & $\begin{array}{l}0.52 \\
(57.7) a b\end{array}$ & \begin{tabular}{|l|}
4130.45 \\
$(96.2) \mathrm{abc}$
\end{tabular} \\
\hline S7 & $\begin{array}{l}0.34 \\
(61.8) \mathrm{c}\end{array}$ & \begin{tabular}{|l}
2.14 \\
$(61.2) \mathrm{c}$
\end{tabular} & \begin{tabular}{|l|}
770.51 \\
$(78.9) \mathrm{c}$
\end{tabular} & $\begin{array}{l}2327.07 \\
(79.1) \mathrm{a}\end{array}$ & $\begin{array}{l}1.97 \\
(88.8) a b\end{array}$ & \begin{tabular}{|l|}
5629.40 \\
$(97.2) \mathrm{ab}$
\end{tabular} \\
\hline S8 & $\begin{array}{l}0.85 \\
(84.7) a b\end{array}$ & \begin{tabular}{|l|}
5.27 \\
$(84.3) a b$
\end{tabular} & $\begin{array}{l}1901.46 \\
(91.4) \mathrm{ab}\end{array}$ & $\begin{array}{l}982.14 \\
(50.5) b c\end{array}$ & $\begin{array}{l}0.57 \\
(61.4) a b\end{array}$ & \begin{tabular}{|l}
872.16 \\
$(82.1) \mathrm{cd}$
\end{tabular} \\
\hline S9 & $\begin{array}{l}0.20 \\
(35.0) \mathrm{c}\end{array}$ & \begin{tabular}{|l|}
1.22 \\
$(32.0) \mathrm{c}$
\end{tabular} & $\begin{array}{l}441.12 \\
(61.1) \mathrm{c}\end{array}$ & $\begin{array}{l}740.97 \\
(34.4) b c\end{array}$ & $\begin{array}{l}3.53 \\
(93.8) \mathrm{ab}\end{array}$ & $\begin{array}{l}1166.55 \\
(86.6) \mathrm{cd}\end{array}$ \\
\hline S10 & $\begin{array}{l}0.83 \\
(84.3) a b\end{array}$ & \begin{tabular}{|l|}
5.16 \\
$(83.9) a b$
\end{tabular} & $\begin{array}{l}1860.86 \\
(91.3) \mathrm{ab}\end{array}$ & $\begin{array}{l}947.85 \\
(48.7) b c\end{array}$ & $\begin{array}{l}0.68 \\
(67.7) a b\end{array}$ & $\begin{array}{l}1653.20 \\
(90.6) \mathrm{cd}\end{array}$ \\
\hline Control $^{\mathrm{a}}$ & $0.133 \mathrm{c}$ & $0.833 \mathrm{c}$ & $162.677 \mathrm{c}$ & $486.328 \mathrm{c}$ & $0.216 \mathrm{~b}$ & $155.947 \mathrm{~d}$ \\
\hline $\mathrm{p}$ value & $<0.0001$ & $\begin{array}{l}< \\
0.0001\end{array}$ & $<0.0001$ & $<0.0001$ & 0.050 & $<0.0001$ \\
\hline Significant & Yes & Yes & Yes & Yes & Yes & Yes \\
\hline
\end{tabular}

S1: Serratia marcescens NGAS9, S2: Serratia liquefaciens KIBS5, S3: Klebsiella oxytoca MWAKS1, S4: Enterobacter tabaci MATS3, S5: Enterobacter tabaci LUTS2, S6: Enterobacter asburiae MWAKS5, S7: Citrobacter freundii MWANS4, S8: Enterobacter tabaci MPUS2, S9: Klebsiella grimontii LUTS1, S10: Enterobacter ludwigii BUMS

Values are means of three replicates with \% increase relative to the control in parenthesis. Means with similar letters within the same columns are not significantly different (ANOVA + Tukey's $\mathrm{HSD} ; p<0.05)$

${ }^{\mathrm{a}}$ Un-inoculated control experiment 
different rhizobacterial treatments on the nutrient concentration in potato tubers in the screen house experiment are provided in Table 5.

All the studied nutrients in the potato tubers were significantly different $(p<0.05)$ across the different rhizobacterial treatments and the un-inoculated control. The greatest $\mathrm{N}$, protein, and $\mathrm{P}$ increments $(>85 \%)$ were observed for the treatments with $S$. marcescens NGAS9, E. tabaci MATS3, and E. asburiae MWAKS5. For K, E. tabaci MWATS 3 yielded the highest average of $2741.86 \mathrm{mg} \mathrm{kg}^{-1}$ corresponding to an $82.3 \%$ increment over the un-inoculated control for which the average $\mathrm{K}$ content was $486.33 \mathrm{mg} \mathrm{kg}^{-1}$. Similar results were observed for $\mathrm{Fe}$ quantity in potato tubers where the same treatment resulted in tubers with an average $\mathrm{Fe}$ content of $6.63 \mathrm{mg} \mathrm{kg}{ }^{-1}$ corresponding to a $96.7 \%$ increment over the control which recorded an average $\mathrm{Fe}$ content of $0.126 \mathrm{mg} \mathrm{kg}^{-1}$. Interestingly, the rhizobacterial treatments resulted in tubers with improved $\mathrm{Zn}$ content to a great extent over the un-inoculated controls by between $90 \%$ and $97 \%$. The highest $\mathrm{Zn}$ content of $6429.97 \mathrm{mg} \mathrm{kg}^{-1}$ was recorded for the treatment with E. tabaci MATS3, an increment of $97.6 \%$ over the control whose tubers had an average $\mathrm{Zn}$ content of $155.95 \mathrm{mg} \mathrm{kg}^{-1}$.

\section{Discussions}

\section{Cultural, Microscopic, Biochemical, and Carbohydrate Utilization Properties of the Isolates}

The rhizobacterial isolated exhibited a broad range of morphological features in terms of their colony forms, indicating their relative diversity. All isolates were Gram-negative, agreeing with other reports that that plant rhizospheres are predominantly colonized by Gram-negative bacterial communities. For instance, in a recent study by Mujahid et al. (2015), up to $90 \%$ of all studied rhizobacterial isolates from various crop fields, respectively, were also Gram-negative.

Only 3 out of the 10 potato rhizobacterial isolates in this study did not exhibit any form of motility in the MTM. Rhizobacterial motility is an important property that enables bacteria to reach the plant root exudates and flagella-driven chemotaxis is very critical for successful root colonization (Turnbull et al. 2001). Half of the isolates were MR-positive, indicating their ability to produce organic acids which are important in the solubilization of inorganic P (Adeleke et al. 2017). Similarly, the rhizobacterial isolates were all positive for catalase production and some isolates exhibited very strong catalase activities. Catalases are enzymes that act as defense mechanisms for bacteria to detoxify, neutralize, repair, or escape oxidative damages and bactericidal effects of reactive oxygen species like $\mathrm{H}_{2} \mathrm{O}_{2}$ (Mumtaz et al. 2017). Except for $K$. oxytoca MWAKS1, all the isolates also exhibited citrate utilization which is thought to play a significant role in competitive root colonization and maintenance of bacteria in the rhizosphere (Turnbull et al. 2001).

Half of the potato rhizobacterial isolates exhibited $\mathrm{H}_{2} \mathrm{~S}$ production. The reduction of sulfide and other sulfate compounds into $\mathrm{H}_{2} \mathrm{~S}$ is thought to diminish sulfur 
availability in the soil for plants and is thus not a desirable trait for soil fertility (Choudhary et al. 2018). The isolates all exhibited indole-production in tryptophanamended cultures, showing their corresponding abilities to produce tryptophanases (Das et al. 2019). Similarly, the rhizobacterial isolates were all positive for the O-F test, indicating their saccharolytic nature which is an important trait for rhizosphere colonization.

The rhizobacterial isolates exhibited varying capacities to metabolize different $\mathrm{CHO}$. A number of them were capable of metabolizing all the sugars but some could not metabolize lactose, sorbitol, and dulcitol. The rhizosphere is generally a nutrientrich microenvironment due to the presence of rhizodeposits and root exudates with different chemical compositions (Kumar et al. 2018). This can explain the diverse ability of the isolates to utilize different substrates for growth as may be provided for in their natural environments. Substrate preference may confer certain selective advantages in the rhizosphere and multisubstrate utilization may enable rhizobacteria to diversify their nutrient sources for efficient rhizosphere colonization (Zahlnina et al. 2018).

\section{In vitro Plant Growth-Promoting Activities of the Potato Rhizobacterial Isolates}

The potato rhizobacterial isolates exhibited varying $\mathrm{P}, \mathrm{Zn}$, and $\mathrm{K}$ solubilization capacities. The average quantities of solubilized $\mathrm{P}$ ranged from 60.96 to $163.47 \mathrm{mg} \mathrm{mL} \mathrm{m}^{-1}$ which is higher compared to previously reported averages for potato rhizobacterial isolates, for example, in studies by Naqqash et al. (2016) where the averages ranged from 30.71 to $141.23 \mathrm{mg} \mathrm{L}^{-1}$. The best $\mathrm{P}$ solubilizers were $E$. tabaci LUTS 2, E. tabaci MPUS2, and S. liquefaciens KIBS5 with average quantities of $115.88,112.59$, and $117.43 \mathrm{mg} \mathrm{L}^{-1}$ of solubilized P, respectively. The solubilization of $\mathrm{P}$ is proposed to occur through acidification by organic acids and results in the production of di- and mono-basic phosphates which are the only plantavailable P forms (Awais et al. 2019). The production of organic acids by the rhizobacterial strains in the present study was evidenced in the biochemical assays and can explain their P solubilization abilities and illustrate how valuable they can be in improving potato $\mathrm{P}$ nutrition.

Serratia marcescens NGAS9, with average ZSI of 2.94 and E. ludwigii BUMS1, with an average of $130.26 \mathrm{mg} \mathrm{L}^{-1}$ of solubilized $\mathrm{Zn}$ exhibited the best $\mathrm{Zn}$ solubilization abilities in the qualitative and quantitative assays, respectively. Although $\mathrm{Zn}$ is a micronutrient, its adequate supply is required for proper potato yields (Vreugdenhil 2007). Since only a small portion of $\mathrm{Zn}$ occurs in plant-available forms in most soils, $\mathrm{Zn}$ solubilizing bacteria (ZSB) such as the ones identified in the present study have the potential of improving the $\mathrm{Zn}$ utilization in potato grown soils (Aloo et al. 2019).

Except for a few isolates, the $\mathrm{K}$ solubilization abilities of the potato rhizobacterial isolates followed similar trends to $\mathrm{P}$ and $\mathrm{Zn}$ solubilization abilities. Two isolates $C$. freundii MWANS4 and E. ludwigii BUMS1 particularly showed good $\mathrm{K}$ 
solubilization abilities in the quantitative assays by yielding averages of 112.98 and $125.26 \mathrm{mg} \mathrm{L}^{-1}$ of solubilized K, respectively. Evidence suggests that about $98 \%$ of $\mathrm{K}$ occurs in soils in fixed forms and only about $2 \%$ is available in plant-accessible forms (Meena et al. 2018). As such, efficient KSB such as the ones identified in the present study can significantly enhance potato $\mathrm{K}$ nutrition.

All the potato rhizobacterial isolates produced IAA in tryptophan-amended culture media similar to reports by Naqqash et al. (2016). Indole-3-acetic acid is a rhizobacterial PGP hormone that is important for the proliferation of lateral roots and root hairs and enhancement of plant mineral nutrients uptake (Kumar et al. 2018). The average IAA quantity produced by the isolates in the present study was $5.57 \pm 4.51 \mu \mathrm{g} \mathrm{mL}^{-1}$. In a recent study by Jadoon et al. (2019) in Pakistan, lower IAA average quantities of only $2.09 \mu \mathrm{g} \mathrm{mL}^{-1}$ were reported but geographical differences could explain this variation. The isolates generally produced lesser quantities of GA with an average of only $0.423 \pm 0.420 \mu \mathrm{g} \mathrm{mL}^{-1}$. The best GA producer was $E$. tabaci MATS3 with an average of $1.27 \mu \mathrm{gL}^{-1}$. Unlike IAA, reports on rhizobacterial GA production are scanty (Amar et al. 2013), yet GA production is one of the rhizobacterial PGP mechanisms (Aloo et al. 2019).

The average $\mathrm{N}_{2}$-fixation zones and quantities of $\mathrm{NH}_{3}$ were $1.153 \pm 0.440 \mathrm{~cm}$ and $27.97 \pm 21.09 \mathrm{mg} \mathrm{L}^{-1}$, respectively. Serratia marcescens NGAS9, with an average $\mathrm{N}_{2}$ fixation zone of $1.70 \mathrm{~cm}$ and E. ludwigii BUMS1, with an average $\mathrm{NH}_{3}$ of $79.84 \mathrm{mg} \mathrm{L}^{-1}$ yielded the best results in this assay. The diazotrophic abilities of the potato rhizobacteria established in the present investigation indicate the critical role they could be playing in the potato rhizosphere. Although diazotrophy is a common trait in legume symbioses, nitrogenase genes are present in diverse bacterial taxa (Gyaneshwar et al. 2011). Such traits can be optimized and exploited to promote $\mathrm{N}$ nutrition in nonlegumes such as the potato using the diazotrophic strains identified in the present study.

The potato rhizobacterial isolates were all capable of producing siderophores which are important metabolites with a high affinity for binding Fe and promoting its availability to plants (Mhlongo et al. 2018). Interestingly, the present isolates showed higher siderophore production abilities than has been reported in other studies for potato rhizobacteria. For instance, the average SU obtained for the isolates in the present investigation was $26.14 \pm 18.25 \%$ while in studies by Pathak et al. (2019), potato rhizobacteria produced lower SU means $(<11.97 \%)$. Very few potato rhizobacteria have been associated with the siderophore production trait (Aloo et al. 2019), and these siderophore-producing rhizobacterial isolates are important candidates for potato biofertilization.

\section{Effects of the Rhizobacterial Treatments on Growth and Yield of Potted Potatoes}

The present study also evaluated the effects of indigenous rhizobacterial treatments on various growth parameters of potted potato under screen house conditions. The results showed that most of the rhizobacterial treatments reduced the DTE and DTF 
of the potato plants by up to $7.35 \%$ and $32.68 \%$, respectively, relative to the uninoculated controls. Increased germination rates and seedling vigor in plants following inoculation with beneficial rhizobacterial strains are advanced to occur as a result of phytohormone production that enhances growth by stimulating root elongation and development (Ahemad and Kibret 2014).

Except for the number and weight of tubers in the present study, the rest of the potato growth parameters were not significantly different across the treatments and the control treatment. Nevertheless, the rhizobacterial treatments still resulted in increased growth attributes of the plant. For instance, the potato shoot weights were increased by $22-88 \%$ upon rhizobacterial inoculation. Such results can also be attributed to the stimulation of root development and nutrient uptake by rhizobacterial PGP hormones (Kumar et al. 2018), whose production was also established for the present rhizobacterial inocula. Contrary to the expectation, $E$. ludwigii BUMS resulted in average potato shoot length and weight that were less than those of the un-inoculated control by $3.94 \%$ and $5.94 \%$, respectively. The failure of rhizobacterial inocula to produce the desired results during in planta investigations is probably due to the inabilities to establish themselves in the rhizosphere (Istifadah et al. 2018).

The potato rhizospheric soils were also greatly influenced by the rhizobacterial treatments. Most treatments resulted in reduced $\mathrm{pH}$ levels relative to the control and increased $\mathrm{N}, \mathrm{P}, \mathrm{K}, \mathrm{Zn}$, and $\mathrm{Fe}$ contents in the potato rhizospheres, signifying rhizosphere acidification which is commonly associated with the solubilization of nutrients in the soil. The increased availability of $\mathrm{N}$ and $\mathrm{P}$ in the rhizospheric soils may be attributed to $\mathrm{N}_{2}$ fixation and $\mathrm{P}$ solubilization by the rhizobacterial inocula as advanced by Sood et al. (2018). The Fe contents in the potato rhizospheric soils increased by up to $99.7 \%$ relative to the un-inoculated control following rhizobacterial inoculation, signifying the excellent Fe-mobilization abilities by the rhizobacterial inocula. The soil OC and OM contents also increased significantly for most of the treatments relative to the un-inoculated control.

The present study established that most of the rhizobacterial treatments resulted in tubers with increased nutrient contents, demonstrating improved nutrient uptake and accumulation by the treated plants. This can mostly be attributed to the multitrait inoculants used to treat the potato plants. For instance, the increased uptake and accumulation of $\mathrm{N}$ and $\mathrm{P}$ may have been due to increased fractions of the minerals in the rhizospheric soils mediated by the rhizobacterial treatments through $\mathrm{N}_{2}$ fixation and $\mathrm{P}$ solubilization, respectively, as similarly observed in wheat by Sood et al. (2018). The inoculation of seed potato tubers with $S$. marcescens NGAS9, $S$. liquefaciens KIBS5, and E. asburiae MWAKS5 resulted in tubers with significantly higher $\mathrm{N}$ and protein contents, a clear indication of their efficient diazotrophic roles. Interestingly, the treatment of potato seed tubers with $C$. freundii MWANS4 and $K$. grimontii LUTS1, despite exhibiting $\mathrm{N}_{2}$ fixation abilities in the in vitro studies, did not lead to significant increments on the average concentration of $\mathrm{N}$ and protein in the potato tubers relative to the un-inoculated control, probably due to the inability to establish adequately themselves in the potato rhizosphere. 


\section{Conclusions}

The study establishes the importance of indigenous rhizobacterial communities in the biofertilization of potato which can be exploited for its sustainable cultivation. The selected potato rhizobacterial isolates demonstrated efficient $\mathrm{N}_{2}$-fixing, P-solubilizing, and IAA, siderophores producing abilities. All these characteristics are important PGP traits and have been found effective in positively improving the growth of potted potato plants under screen house conditions. In sustainable crop production, the focus should not only be on increasing crop productivity but also the nutritional value of the food produced for food security. Apart from improving the potato growth parameters relative to the control, the rhizobacterial treatments also enhanced nutrient availability in the rhizospheric soils and improved the potato tuber nutrient contents. The studied isolates are, therefore, potential candidates in future field applications and sustainable cropping of potato in Tanzania.

\section{References}

Adeleke R, Mwangburuka C, Oboirien B (2017) Origins, roles and fate of organic acids in soils: a review. S Afr J Bot 108:393-406. https://doi.org/10.1016/j.sajb.2016.09.002

Ahemad M, Kibret M (2014) Mechanisms and applications of plant growth promoting rhizobacteria: current perspective. J King Saud Univ-Sci 26:1-20. https://doi.org/10.1016/j. jksus.2013.05.001

Aloo BN, Mbega ER, Makumba BA (2019) Rhizobacteria-based technology for sustainable cropping of Potato (Solanum tuberosum L.). Potato Res:1-21. https://doi.org/10.1007/s11540019-09432-1

Aloo BN, Mbega ER, Makumba BA, Hertel R, Danel R (2020) Molecular identification and in vitro plant growth-promoting activities of culturable Potato (Solanum tuberosum L.) rhizobacteria in Tanzania. Potato Res. https://doi.org/10.1007/s11540-020-09465-x

Amar JD, Kumar M, Kumar R (2013) Plant growth promoting rhizobacteria (PGPR): an alternative of chemical fertilizer for sustainable, environment friendly agriculture. Res J Agric For 1:21-23

AOAC (1995) Official methods of analysis, 16th edn. Association of Official Analytical Chemists, Washington, DC

Awais M, Tariq M, Ali Q, Khan A, Ali A, Nasir IA, Husnain T (2019) Isolation, characterization and association among phosphate solubilizing bacteria from sugarcane rhizosphere. Cytol Genet 53:86-95. https://doi.org/10.3103/S0095452719010031

Batista BD (2012) Promoção De Crescimento Em Milho (Zea mays L.) Por rizobactérias associadas à cultura do guaranazeiro (Paullinia cupana var. sorbilis). Dissertation, University of Sao Paulo

Bremmer JM, Mulvaney CS (2015) Nitrogen total. In: Page AL (ed) Methods of soil analysis, 2nd edn. American Society of Agronomy, Madison, pp 595-624

Chaurasia S, Gupta AD (2014) Handbook of water, air and soil analysis. International Science Congress Association, Madhya Pradesh

Chi CM, Wang ZC (2010) Characterizing salt-affected soils of Songnen plain using saturated paste and 1:5 soil to-water extraction methods. Arid Land Res Manag 24:1-11. https://doi.org/10. 1080/15324980903439362

Choudhary M, Ghasal P, Yadav R, Meena V, Mondal T, Bisht J (2018) Towards plant-beneficiary rhizobacteria and agricultural sustainability. In: Meena VS (ed) Role of rhizospheric microbes in soil: volume 2: nutrient management and crop improvement. Springer Nature, Singapore, pp 146 
Das S, Nurunnabi TR, Parveen R, Mou AN, Islam ME, Islam KMD, Rahman M (2019) Isolation and characterization of indole acetic acid producing bacteria from rhizosphere soil and their effect on seed germination. Int J Curr Microbiol Appl Sci 8:1237-1245

Edi-Premona M, Moawad MA, Vlek PLG (1996) Effect of phosphate- solubilizing Pseudomonas putida on growth of maize and its survival in the rhizosphere. Indones J Crop Sci 11:13-23

FAO (2008) International year of the potato: new light on a hidden treasure. Food and Agriculture Organization of the United Nations, Rome

Fasim F, Ahmed N, Parsons R, Gadd GM (2002) Solubilization of zinc salts by a bacterium isolated from the air environment of a tannery. FEMS Microbiol Lett 213:1-6

George H, Ed H (2011) A summary of N, P, and K research with tomato in Florida. The Institute of Food and Agricultural Sciences, University of Florida, Gainesville

Goswami D, Dhandhukia PC, Patel P, Thakker JN (2014) Screening of PGPR from saline desert of Kutch: growth promotion in Arachis hypogea by Bacillus licheniformis A2. Microbiol Res 169: 66-75. https://doi.org/10.1016/j.micres.2013.07.004

Gyaneshwar P, Hirsch AM, Moulin L, Chen WM, Elliot GN, Bontemps C, Santos PE, Gross E, Reis FB Jr, Sprent JI, Young PW, James EK (2011) Legume-nodulating betaproteobacteria: diversity, host range, and future prospects. Mol Plant-Microbe Interact 24:1276-1288. https://doi.org/10. 1094/mpmi-06-11-0172

Holbrook AA, Edge WLW, Bailey F (1961) Spectrophotometric method for determination of gibberellic acid in gibberellins. ACS, Washington, DC

Hopkins BG, Hornek DA, MacGuidwin AE (2014) Improving phosphorus use efficiency through potato rhizosphere modification and extension. Am J Potato Res 91:161-174. https://doi.org/10. 1007/s12230-014-9370-3

Hugh R, Leifson E (1953) The taxonomic significance of fermentative versus oxidative metabolism of carbohydrates by various gram negative bacteria. J Bacteriol 66:24

Istifadah N, Pratama N, Taqwim S, Sunarto T (2018) Effects of bacterial endophytes from potato roots and tubers on potato cyst nematode (Globodera rostochiensis). Biodiversitas 19:47-51. https://doi.org/10.13057/biodiv/d190108

Jackson ML (1973) Soil chemical analysis, 2nd edn. Prentice Hall of India, New Delhi

Jadoon S, Afzal A, Asad SA, Sultan T, Tabassum B, Umer M, Asif M (2019) Plant growth promoting traits of rhizobacteria isolated from Potato (Solanum tuberosum L.) and their antifungal activity against Fusarium oxysporum. J Anim Plant Sci 29:1026-1036

Kumar A, Patel JS, Meena VS (2018) Rhizospheric microbes for sustainable agriculture: an overview. In: Meena V (ed) Role of rhizospheric microbes in soil. Springer Nature, Singapore, pp 1-31

Manzira C (2011) Potato production handbook. Potato Seed Association, Harare

Meena SV, Maurya BR, Meena SK, Mishra PK, Bisht JK, Pattanayak A (2018) Potassium solubilization: strategies to mitigate potassium deficiency in agricultural soils. Glob J Biol Agric Health Sci 7:1-3

Mhlongo MI, Piater LA, Madala NE, Labuschagne N, Dubery IA (2018) The chemistry of plantmicrobe interactions in the rhizosphere and the potential for metabolomics to reveal signaling related to defense priming and induced systemic resistance. Front Plant Sci 9:112. https://doi. org/10.3389/fpls.2018.00112

Miller RO (1995) Extractable chloride nitrate orthophosphate and sulfate-sulfur in plant tissue: $2 \%$ acetic acid extraction. In: Kalra YP (ed) Handbook of reference methods for plant analysis. CRC Press, Boca Raton, pp 115-118

Mujahid YT, Subhan SA, Wahab A, Masnoon J, Ahmed N, Abbas T (2015) Effects of different physical and chemical parameters on phosphate solubilization activity of plant growth promoting bacteria isolated from indigenous soil. J Pharm Nutr Sci 5:64-70

Mumtaz MZ, Ahmad M, Jamil M, Hussain T (2017) Zinc solubilizing Bacillus spp. potential candidates for biofortification in maize. Microbiol Res 202:51-60 
Naqqash T, Hameed S, Imram A, Hanif MK, Majeed A, Van Elsas JD (2016) Differential response of potato toward inoculation with taxonomically diverse plant growth promoting rhizobacteria. Front Plant Sci 7:144. https://doi.org/10.3389/fpls.2016.00144

Pathak D, Lone R, Khan S, Koul KK (2019) Isolation, screening and molecular characterization of free-living bacteria of potato (Solanum tuberosum L.) and their interplay impact on growth and production of potato plant under Mycorrhizal association. Sci Hortic 252:388-397. https://doi. org/10.1016/j.scienta.2019.02.072

Payne SM (1993) Iron acquisition in microbial pathogenesis. Trends Microbiol 1:66-69. https://doi. org/10.1016/0966-842X(93)90036-Q

Pradhan P (2016) KOH mount preparation: principle, procedure and observation. Microbiology and Infectious Diseases. http://microbesinfo.com/2016/05/koh-mount-preparation-principle-proce dure-and-observation/. Accessed 28 Apr 2018

Sambrook J, Russell DW (2001) Molecular cloning: a laboratory manual, 1st edn. Cold Spring Harbor Laboratory, New York

Schwyn B, Neilands JB (1987) Universal chemical assay for the detection and determination of siderophores. Anal Biochem 60:47-56

Simmons JS (1926) A culture medium for differentiating organisms of typhoid-colon aerogenes groups and for isolation of certain fungi. J Infect Dis 39:209

Sindhu SS, Gupta SK, Dadarwal KR (1999) Antagonistic effect of Pseudomonas spp. on pathogenic fungi and enhancement of plant growth in green gram (Vigna radiata). Biol Fertil Soils 29: $62-68$

Somasegaran P, Hoben HJ (1994) Handbook for rhizobia. Methods in legume-rhizobium technology. Springer, Heidelberg

Sood G, Kaushal R, Chauhan A, Gupta S (2018) Indigenous plant-growth-promoting rhizobacteria and chemical fertilisers: impact on wheat (Triticum aestivum) productivity and soil properties in North Western Himalayan region. Crop Pasture Sci 69:460-468

Tedesco MJ, Gianello C, Bissani CA, Bohnen H, Volkweiss SJ (1995) Analysis of soil, plants and other materials, 2nd edn. Federal University of Rio Grande do Sul, Porto Alegre

Tran TS, Simard RR (1993) Mehlich III - extractable elements. In: Carter MR (ed) Soil sampling and methods of analysis, 2nd edn. CRC Press, Boca Raton, pp 43-49

Turnbull GA, Morgan JAW, Whipps JM, Saunders JR (2001) The role of bacterial motility in the survival and spread of Pseudomonas fluorescens in soil and in the attachment and colonisation of wheat roots. FEMS Microbiol Ecol 36:21-23. https://doi.org/10.1111/j.1574-6941.2001. tb00822.x

Vincent JM (1970) A manual for the practical study of the root-nodule Bacteria. Blackwell, Oxford, UK

Vreugdenhil D (2007) Potato biology and biotechnology - advances and perspectives. Elsevier, Amsterdam

Wahyudi AT, Astuti RP, Widyawati A, Meryandini AA, Nawagsih AA (2011) Characterization of Bacillus $s p$. strains isolated from rhizosphere of soybean plants for their use as potential plant growth promoting rhizobacteria. J Microbiol Antimicrob 3:34-40

Walkley AJ, Black IA (1934) Estimation of soil organic carbon by the chromic acid titration method. Soil Sci 37:29-38

Zahlnina K, Louie K, Hao Z, Mansoori N, Da Rocha UN, Shi S, Cho H, Karaoz U, Loqué D, Powen BP, Firestone M, Northern TR, Brodie EL (2018) Dynamic root exudate chemistry and microbial substrate preferences drive patterns in rhizosphere microbial community assembly. Nat Microbiol 3:480 
Open Access This chapter is licensed under the terms of the Creative Commons Attribution 4.0 International License (http://creativecommons.org/licenses/by/4.0/), which permits use, sharing, adaptation, distribution and reproduction in any medium or format, as long as you give appropriate credit to the original author(s) and the source, provide a link to the Creative Commons license and indicate if changes were made.

The images or other third party material in this chapter are included in the chapter's Creative Commons license, unless indicated otherwise in a credit line to the material. If material is not included in the chapter's Creative Commons license and your intended use is not permitted by statutory regulation or exceeds the permitted use, you will need to obtain permission directly from the copyright holder.

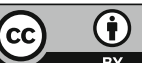

